\title{
Synthesis and Characterization of Co-doped Manganese Ferrite Nanoparticles
}

\author{
Amer Mahmoud Amer Hassan, M. Yehia* and M. Kaiser \\ Reactor Physics Department, Nuclear Research Center, Atomic Energy Authority, Cairo, Egypt
}

\begin{tabular}{|c|c|}
\hline ARTICLE INFO & ABSTRACT \\
\hline Article history: & \multirow{11}{*}{ 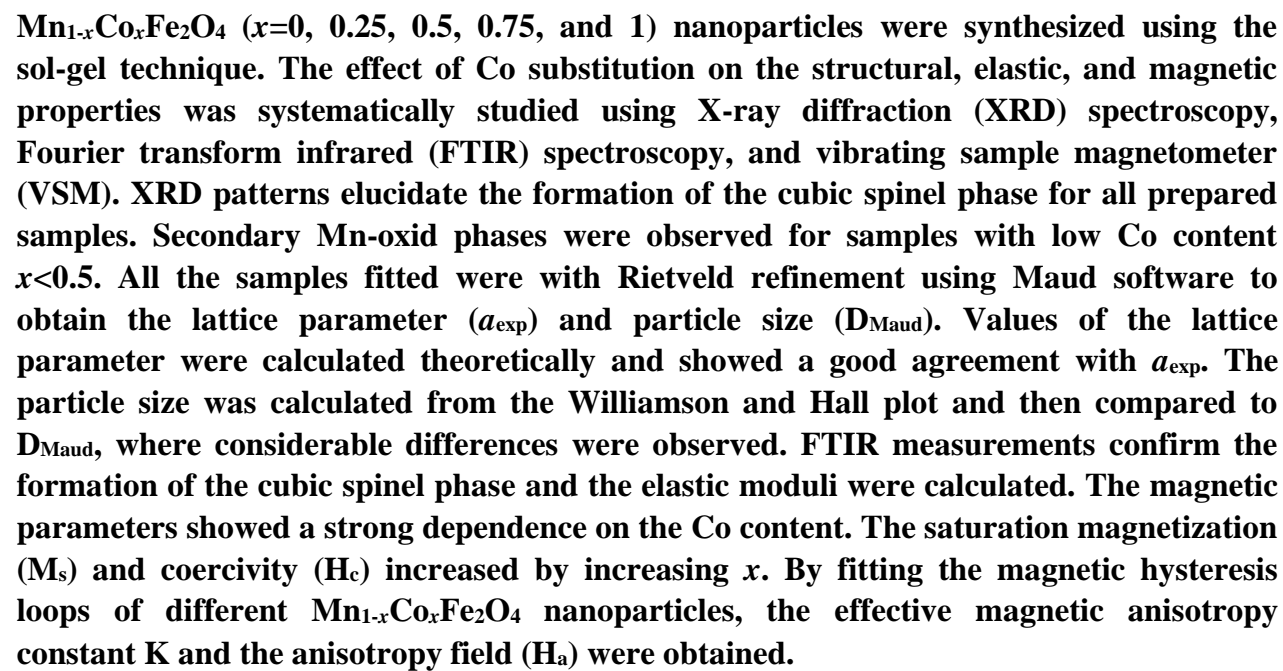 } \\
\hline Received: $25^{\text {th }}$ July 2021 & \\
\hline Accepted: $5^{\text {th }}$ Nov. 2021 & \\
\hline Keywords: & \\
\hline MnCo Ferrite, & \\
\hline & \\
\hline FTIR, & \\
\hline VSM, & \\
\hline Magnetic Anisotropy Constant. & \\
\hline & \\
\hline & \\
\hline
\end{tabular}

\section{INTRODUCTION}

Developing nanodevices, molecular apparatuses, and nano spectroscopies attract interest starting from the fabrication methods and characterization techniques to the final devices' applications. The ferrite nanoparticles have promising applications in the field of molecular transistors, molecular resonant tunneling diodes, memory, and configurational switch, and charged-based memory [1,2]. A typical spinel ferrite has the composition $\left(\mathrm{M}_{1-\delta} \mathrm{Fe}_{\delta}\right)_{\mathrm{A}}\left[\mathrm{M}_{\delta} \mathrm{Fe}_{2-\delta}\right]_{\mathrm{B}} \mathrm{O}_{4}$, where $\mathrm{A}$ refers to the tetrahedral site and $\mathrm{B}$ is the octahedral site. $\mathrm{M}$ denotes divalent ions of the transition elements. The degree of inversion $(\delta)$ represents the concentration of divalent ions in the octahedral site. For a fully inverted spinel ferrite, all the divalent ions occupying the B-site and trivalent $\mathrm{Fe}^{3+}$ ions are equally distributed between the A- and B- sites [3-6]. M can be a mixture of divalent ions, whereas, transition or/and rare earth trivalent ions partially substitute $\mathrm{Fe}^{3+}$ ions [7-10]. Electric and magnetic properties of the ferrite compounds critically depend on the chemical composition, preparation conditions, particle size, and the distribution of the cations between the tetrahedral, and octahedral sites [11-13]. $\mathrm{MnFe}_{2} \mathrm{O}_{4}$ ferrites are considered a partial inverse spinel structure, with an intense octahedral site preference of $\mathrm{Mn}^{2+}$ ions. On the other side, $\mathrm{CoFe}_{2} \mathrm{O}_{4}$ ferrites have a complete inverse spinel structure. Owing to the differences in the size, magnetic moments, and spin orbital coupling between $\mathrm{Mn}^{2+}$ and $\mathrm{Co}^{2+}$ ions, the magnetic properties of the two ferrites vary significantly. Cobalt ferrite is a hard magnetic material with a large coercive field whereas, $\mathrm{Mn}$ ferrite is soft and has a relatively low coercive field. Interestingly, doping is not the only factor that can alter the magnetic properties of ferrite compounds. Different preparation methods and heat treatments of the prepared samples yield particles of different sizes and particle shapes, which will consequently affect the magnetic properties $[11,14,15]$.

In this work, $\mathrm{Mn}_{1-x} \mathrm{Co}_{x} \mathrm{Fe}_{2} \mathrm{O}_{4}$ nanoparticles were prepared using the Sol-gel technique. The influence of increasing Co content on the structural, elastic, and magnetic properties was systematically studied. Both $\mathrm{Mn}^{2+}$ and $\mathrm{Co}^{2+}$ ions are divalent; however, they have different ionic radii and magnetic moments. 
Accordingly, the changes in the structural and magnetic properties are expected. The crystal structure was investigated using X-ray powder diffraction. The Fourier-transform infrared spectroscopy (FTIR) was used to investigate the elastic properties of the prepared samples. The characterization of the magnetic properties was achieved by performing vibrating sample magnetometer (VSM) measurements.

\section{Experimental}

\subsection{Materials and methods}

All the studied ferrites nanoparticles were synthesized using the sol-gel citrate precursor method as described in Figure (1). The nitrates of different elements; $\mathrm{Fe}\left(\mathrm{NO}_{3}\right)_{3} \bullet 9 \mathrm{H}_{2} \mathrm{O}, \quad \mathrm{Mn}\left(\mathrm{NO}_{3}\right)_{2} \bullet 4 \mathrm{H}_{2} \mathrm{O}, \quad$ and $\mathrm{Co}\left(\mathrm{NO}_{3}\right)_{2} \bullet 6 \mathrm{H}_{2} \mathrm{O}$, citric acid $\left(\mathrm{C}_{6} \mathrm{H}_{8} \mathrm{O}_{7} \bullet \mathrm{H}_{2} \mathrm{O}\right)$, and distilled water were used in the preparation procedures. The compounds are prepared by dissolving nitrates and citric acid in an appropriate amount of distilled water. A complete dissolution of the mixture occurs through stirring onto a hot plate at $80{ }^{\circ} \mathrm{C}$. The gels are heated on a hot plate until the complete evaporation of the aqueous solution and fine ashes are obtained. The dried powder was thermally treated at $400{ }^{\circ} \mathrm{C}$ for $4 \mathrm{~h}$.

The purity and structure of the prepared samples were investigated using X-ray diffraction (XRD) (Philips $\mathrm{X}$ 'pert multipurpose diffractometer) with $\mathrm{CuK}_{\alpha}$ radiation $(\lambda=1.5418 \AA)$. The crystal structure was refined and the Rietveld profile method was applied using the Maud software [16]. The Fourier transform infrared (FTIR) measurements of different $\mathrm{Mn}_{1-x} \mathrm{Co}_{x} \mathrm{Fe}_{2} \mathrm{O}_{4}$ samples were performed using Spectrum 100 (Perkin Elmer, USA) in the spectral range of $1000-250 \mathrm{~cm}^{-1}$. the magnetic properties were investigated using a vibrating sample magnetometer VSM (9600-1 LDJ, USA) at room temperature with an applied magnetic field up to $20 \mathrm{kG}$.

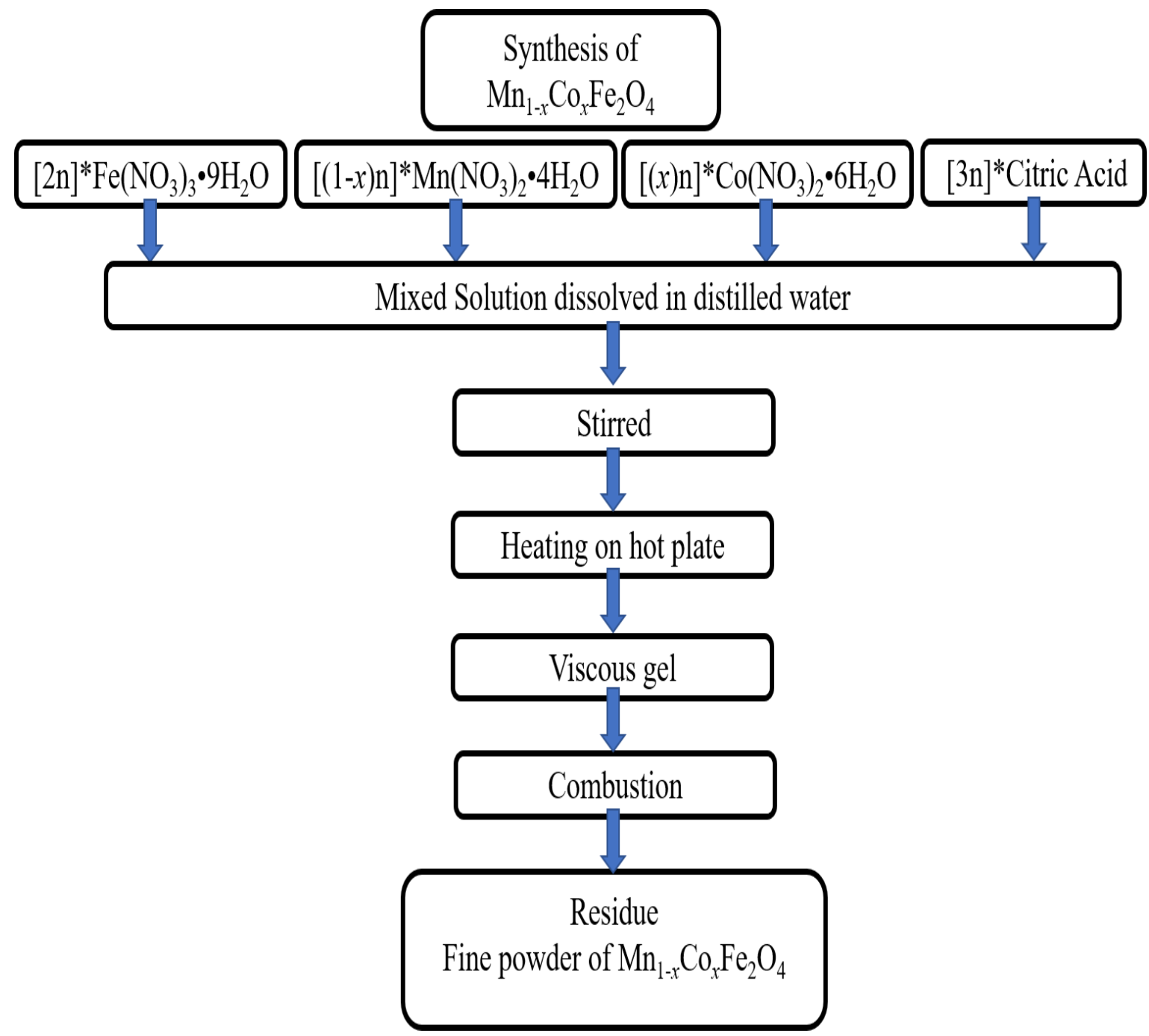

Fig. (1): Flowchart of synthesizing of $\mathrm{Mn}_{1-x} \mathrm{Co}_{x} \mathrm{Fe}_{2} \mathrm{O}_{4}$ nanoparticles 


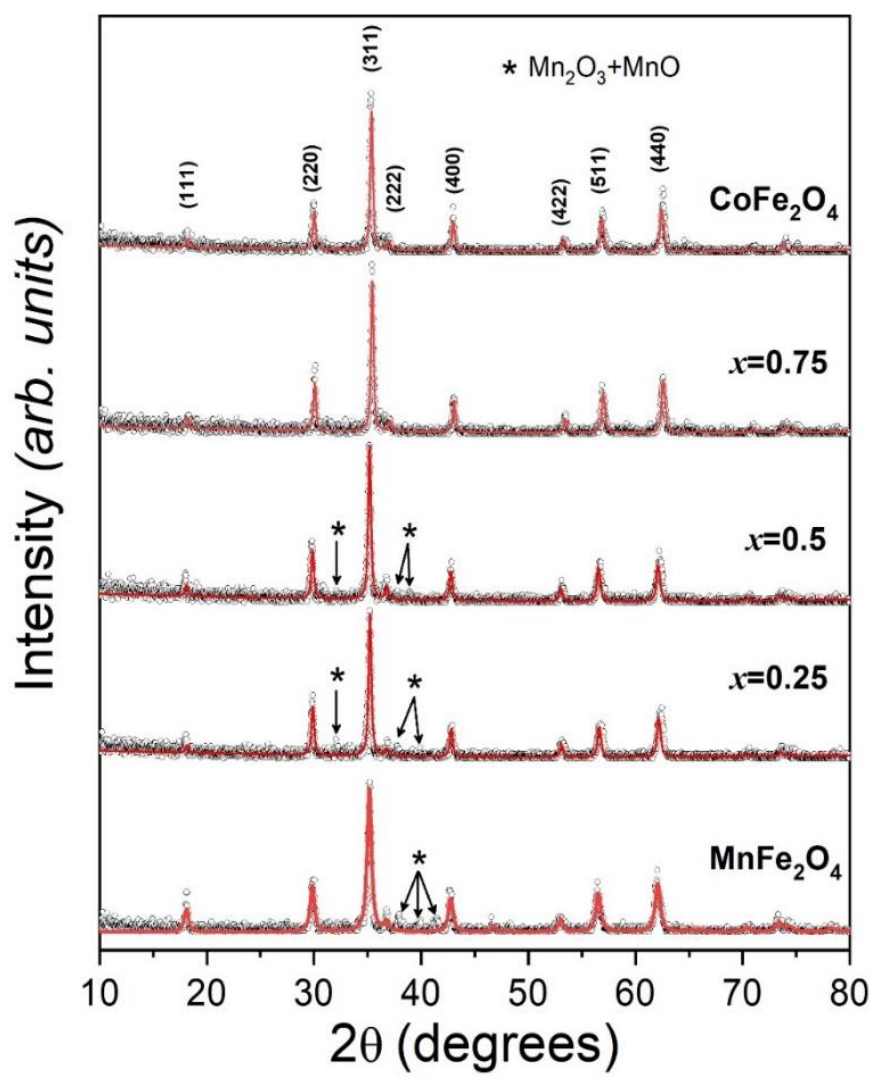

Fig. (2): XRD patterns of $\mathrm{Mn}_{1-x} \mathrm{Co}_{x} \mathrm{Fe}_{2} \mathrm{O}_{4}(x=0,0.25,0.5$, 0.75 and 1) nanoparticles

\section{RESULTS AND DISCUSSION}

\subsection{XRD measurements}

The XRD patterns of the $\mathrm{Mn}_{1-x} \mathrm{Co}_{x} \mathrm{Fe}_{2} \mathrm{O}_{4}$ nanoparticles are shown in Figure (2). All the samples are crystallized in the cubic spinel ferrite phase with the Fd-3m space group. For samples with a high $\mathrm{Mn}$ concentration, $x \leq 0.5$, additional diffraction peaks were observed and identified as $\mathrm{Mn}$ oxide phases ( $\mathrm{MnO}$ and
$\mathrm{Mn}_{2} \mathrm{O}_{3}$ ). The intensity of the secondary phase peaks decreases with increasing the $\mathrm{Co}$ content, and these peaks disappeared in the $\mathrm{Mn}_{0.25} \mathrm{Co}_{0.75} \mathrm{Fe}_{2} \mathrm{O}_{4}$ and $\mathrm{CoFe}_{2} \mathrm{O}_{4}$ samples. The lattice parameter $(a)$ obtained from the Rietveld analysis is listed in Table (1) and shown in Figure (3a). The lattice parameter slightly decreases by introducing $\mathrm{Co}^{2+}$ ions to the unit cell up to $x=0.5$, whereas for further increasing of the Co content, $a$ sharply decreases. The particle size gradually increases by increasing $x$ (Table 2 and Figure $3 b$ ). Using the cation distribution between the A- and B-sites, the theoretical lattice parameter $a_{\text {th }}$ was calculated. The mean ionic radius per molecule of the A-site $\left(r_{A}\right)$ and $B$-site $\left(r_{B}\right)$ is given by [8]:

$$
\begin{gathered}
r_{A}=C_{F e} r\left(F e^{3+}\right) \\
r_{B}=\frac{1}{2}\left[C_{F e} r\left(F e^{3+}\right)+C_{T M} r\left(T M^{2+}\right)\right]
\end{gathered}
$$

Where; $r\left(\mathrm{Fe}^{3+}\right)$ is the ionic radius of $\mathrm{Fe}^{3+}$ in the tetrahedral and octahedral sites, $0.49 \AA$ and $0.645 \AA$, respectively. The $\mathrm{r}\left(\mathrm{TM}^{2+}\right)$ is the ionic radius of $\mathrm{TM}^{2+}$ $\left(\mathrm{Co}^{2+}\right.$, and $\left.\mathrm{Mn}^{2+}\right)$ in the octahedral site, $(0.745 \AA$ and $0.83 \AA$ ), respectively [17]. The concentration of $\mathrm{Fe}^{3+}$ and $\mathrm{TM}^{2+}$ ions in $\mathrm{A}-$ and $\mathrm{B}-$ sites are $\mathrm{C}_{\mathrm{Fe}}$ and $\mathrm{C}_{\mathrm{TM}}$, respectively. The average $(\mathrm{A}-\mathrm{O})$, and $(\mathrm{B}-\mathrm{O})$ bond lengths are $\mathrm{R}_{\mathrm{A}}$ and $\mathrm{R}_{\mathrm{B}}$, respectively and can be expressed as [8]:

$$
\begin{aligned}
& R_{A}=r_{A}+r_{O} \\
& R_{B}=r_{B}+r_{O}
\end{aligned}
$$

Where $\mathrm{r}_{\mathrm{O}}=1.32 \AA$ is the radius of oxygen ion. The lattice parameter $a_{\text {th }}$ can be obtained from [8]:

$$
a_{t h}=\frac{8}{3 \sqrt{3}}\left[\left(r_{A}+r_{O}\right)+\sqrt{3}\left(r_{B}+r_{O}\right)\right]
$$
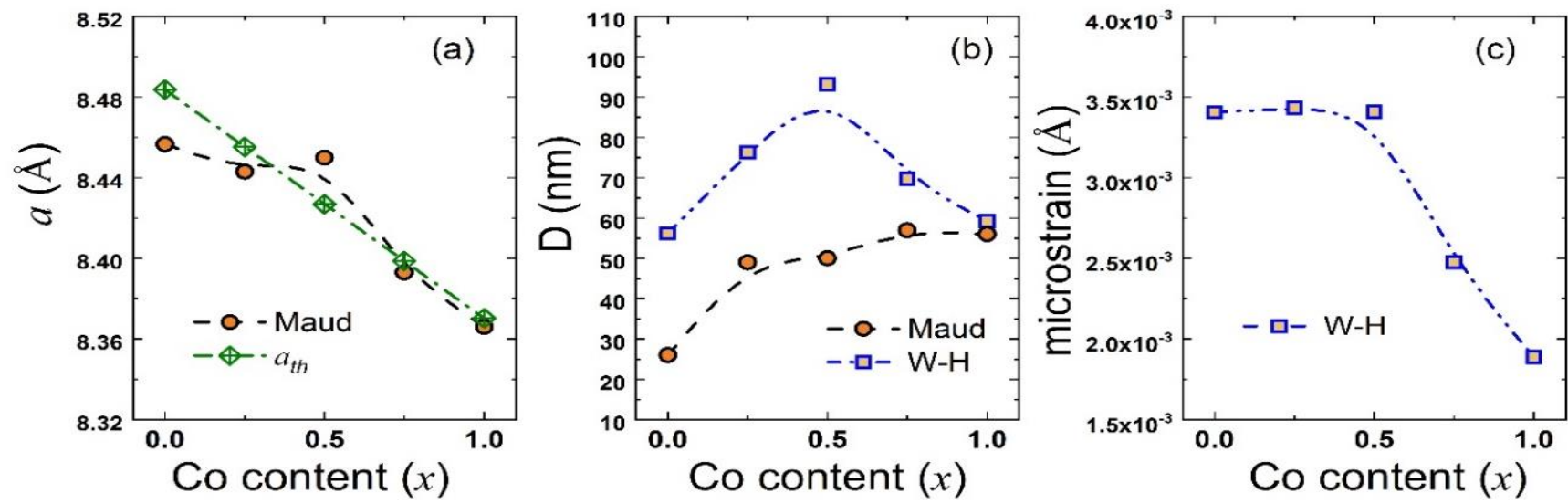

Fig. (3 a): The lattice parameter $a$, b) particle size D calculated from W-H plots, c) Microstrain $\varepsilon$ of different $\mathrm{Mn}_{1-x} \mathrm{Co}_{x} \mathrm{Fe}_{2} \mathrm{O}_{4}$ nanoparticles 
The values of the structure parameters; $a_{\mathrm{th}}, \mathrm{R}_{\mathrm{A}}$, and $\mathrm{R}_{\mathrm{B}}$, are listed in Table (1). The ionic radius of $\mathrm{Co}^{2+}$ ion is smaller than that of $\mathrm{Mn}^{2+}$ ion, and therefore, as shown in Figure (3a), $a_{\text {th }}$ decreases linearly with increasing the Co content. The values of the theoretically calculated lattice parameter $\left(a_{\mathrm{th}}\right)$ are close to the values of $a_{\text {exp }}$. The trend of the decrease of both $a_{\text {th }}$ and $a_{\text {exp }}$ is similar for $x>0.5$. The differences observed in the trend for $x<0.5$ can be attributed to the existence of the secondary phase, which might cause an interstitial substation and increase the uncertainty in Maud fitting. The decrease of the lattice parameter by increasing the Co content can be attributed to the differences in the ionic radii of the $\mathrm{Mn}^{2+}$ and $\mathrm{Co}^{2+}$ ions, whereas, $\mathrm{r}\left(\mathrm{Co}^{2+}\right)<\mathrm{r}\left(\mathrm{Mn}^{2+}\right)$. The $\mathrm{X}$-ray density is given by:

$$
\rho_{x}=\frac{8 M}{N_{A} V}
$$

Where $\mathrm{M}$ is the molecular weight and $\mathrm{V}=a^{3}$ is the volume of the unit cell. The lattice parameter decreases with increasing $x$ and therefore the density increases gradually with the increase of the Co content.
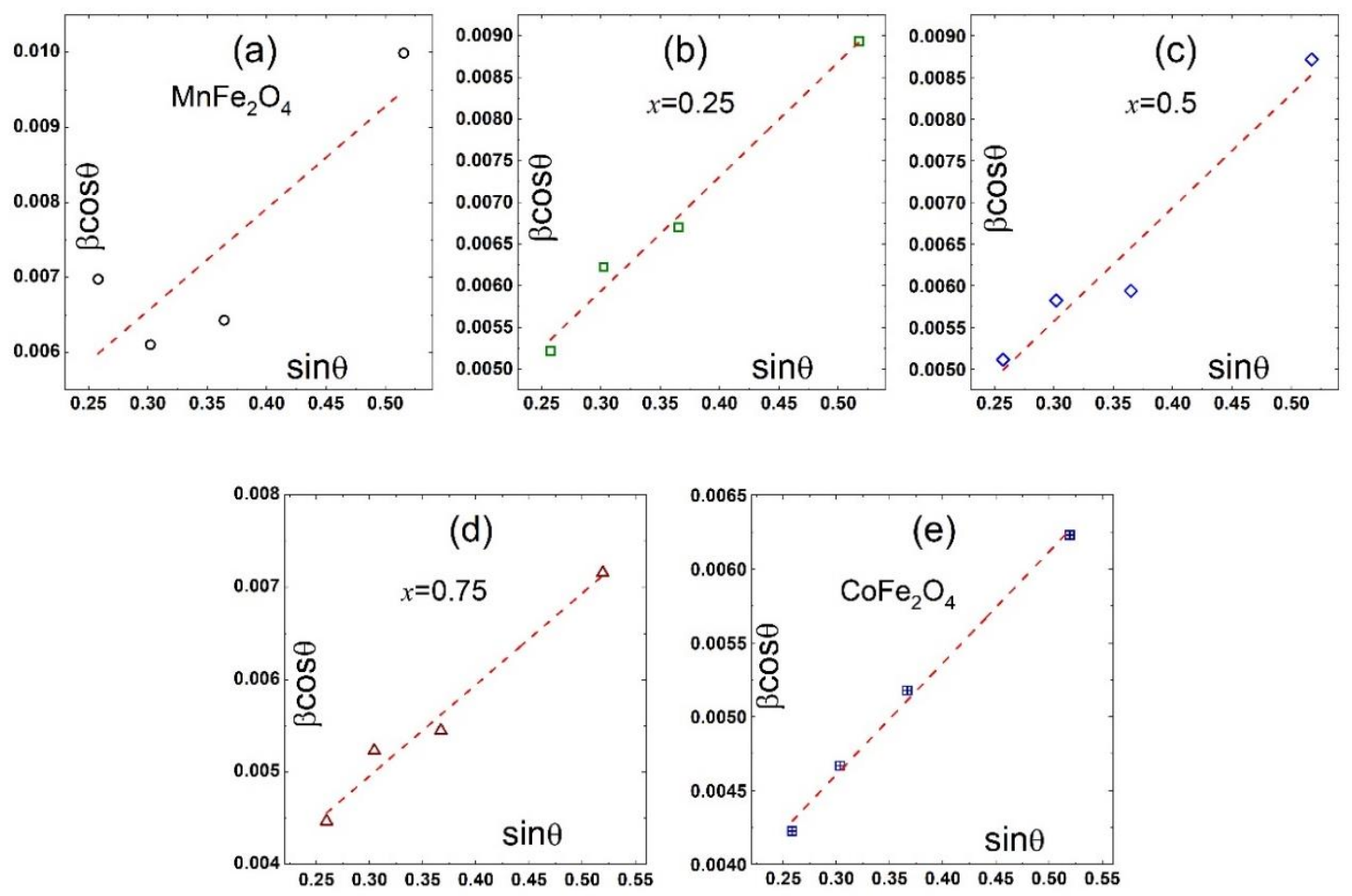

Fig. (4): W-H plots of different $\mathrm{Mn}_{1-x} \mathrm{Co}_{x} \mathrm{Fe}_{2} \mathrm{O}_{4}$ nanoparticles

Table (1): Average bond lengths $\left(\mathbf{R}_{\mathrm{A}}\right.$, and $\left.\mathbf{R}_{\mathrm{B}}\right)$, experimental $\left(a_{\mathrm{exp}}\right)$, theoretical $\left(a_{\mathrm{th}}\right)$ lattice constants, density $\left(\rho_{\mathrm{x}}\right)$, the hopping lengths $\left(L_{A}\right.$, and $\left.L_{B}\right)$, average particle size obtained from Maud fitting ( $D_{\text {Maud }}$, and W-H plots $\left(D_{W-H}\right.$, the microstrain (E) of $\mathrm{Mn}_{1-x} \mathrm{Co}_{x} \mathrm{Fe}_{2} \mathrm{O}_{4}$ nanoparticles

\begin{tabular}{|c|c|c|c|c|c|c|c|c|c|c|}
\hline$x$ & $\begin{array}{l}\mathbf{R}_{\mathbf{A}} \\
(\AA)\end{array}$ & $\begin{array}{l}\mathbf{R}_{\mathbf{B}} \\
(\AA)\end{array}$ & $\begin{array}{l}a_{\mathrm{th}} \\
(\AA)\end{array}$ & $\begin{array}{l}a_{\exp } \\
(\AA)\end{array}$ & $\begin{array}{c}\rho_{\mathrm{x}} \\
\left(\mathrm{gcm}^{-1}\right)\end{array}$ & $\begin{array}{l}\mathbf{L}_{\mathbf{A}} \\
(\AA)\end{array}$ & $\begin{array}{l}\mathbf{L}_{\mathbf{B}} \\
(\AA)\end{array}$ & $\begin{array}{c}\text { D }_{\text {Maud }} \\
\mathbf{n m}\end{array}$ & $\begin{array}{c}\text { D }_{\mathrm{W}-\mathrm{H}} \\
\mathbf{n m}\end{array}$ & $\begin{array}{c}\varepsilon\left(10^{-4}\right) \\
(\AA)\end{array}$ \\
\hline $\mathbf{0}$ & 1.86 & 2.108 & 8.483 & 8.457 & 5.07E3 & 3.662 & 2.99 & 26 & 56 & 34.05 \\
\hline 0.25 & 1.86 & 2.097 & 8.455 & 8.443 & $5.11 \mathrm{E3}$ & 3.656 & 2.985 & 49 & 76 & 34.325 \\
\hline 0.5 & 1.86 & 2.086 & 8.427 & 8.45 & $5.12 \mathrm{E} 3$ & 3.659 & 2.988 & 50 & 93 & 34.075 \\
\hline 0.75 & 1.86 & 2.076 & 8.399 & 8.393 & $5.25 \mathrm{E} 3$ & 3.634 & 2.967 & 57 & 69 & 24.75 \\
\hline 1 & 1.86 & 2.065 & 8.37 & 8.366 & $5.32 \mathrm{E} 33$ & 3.623 & 2.958 & 56 & 59 & 18.875 \\
\hline
\end{tabular}


The average crystallite size and microstrain ' $\varepsilon$ ' values can be obtained from Williamson and Hall $(\mathrm{W}-\mathrm{H})$ equation [18]:

$$
\beta \cos \theta=\frac{\lambda k}{D}+4 \varepsilon \sin \theta
$$

Where $\beta$ is the broadening of the XRD peaks, $\lambda$ is the XRD wavelength $\left(\mathrm{CuK}_{\alpha}\right.$ radiation with $\left.\lambda=1.5418\right)$, $k=0.9, \varepsilon$ microstrain, and $D$ is the particle size. For all the $\mathrm{Mn}_{1-x} \mathrm{Co}_{x} \mathrm{Fe}_{2} \mathrm{O}_{4} \quad(x=0, \quad 0.25, \quad 0.5, \quad 0.75, \quad$ and 1$)$ nanoparticles, XRD peaks (2 20 ), (3 11 1), (2 22 2), (4 00 ) and (4 40 ) were fitted using Gaussian line profiles and from the fitting, values of $\theta$ and $\beta$ were obtained. Figure (4) shows Williamson and Hall plot for all samples. The values of the particle size obtained from the $\mathrm{W}-\mathrm{H}$ plot are listed in Table (1) and compared to that obtained from Maud fitting in Fig. (3b). A considerable difference was observed in both the values and trends of $\mathrm{D}_{\text {Maud }}$ and $\mathrm{D}_{\mathrm{W}-\mathrm{H}}$. This difference can be related to the observation of the secondary $\mathrm{Mn}$ oxide phases for $x<0.5$, which influences the width of the XRD peaks and complicate the calculation of the particle size. The values of the microstrain have a behavior similar to the lattice parameter (Fig. 3c), whereas $\varepsilon$ shows a clear decrease for $x>0.5$. The decrease of the microstrain can be considered as a result of substituting $\mathrm{Mn}^{2+}$ ions with smaller $\mathrm{Co}^{2+}$ ions [19]. Simultaneously, the coexistence of multicrystallographic phases causes additional strain. This strain is relived for single phases $\mathrm{Mn}_{0.25} \mathrm{Co}_{0.75} \mathrm{Fe}_{2} \mathrm{O}_{4}$ and $\mathrm{CoFe}_{2} \mathrm{O}_{4}$ nanoparticles.

The hopping lengths, $\mathrm{L}_{\mathrm{A}}$, and $\mathrm{L}_{\mathrm{B}}$ represent the distance between the magnetic ions in the tetrahedral sites and octahedral sites, respectively. $\mathrm{L}_{\mathrm{A}}$ and $\mathrm{L}_{\mathrm{B}}$ can be calculated as [20]:

$$
\begin{aligned}
& L_{A}=\frac{\sqrt{3}}{4} a \\
& L_{B}=\frac{\sqrt{2}}{4} a
\end{aligned}
$$

The values $L_{A}$ and $L_{B}$ are shown in Table (1). Because of the decreased lattice parameter, both lengths decrease for $x>0.5$. Such a decrease of $\mathrm{L}_{\mathrm{A}}$ and $\mathrm{L}_{\mathrm{B}}$ would logically strengthen the magnetic interaction with increasing the Co content.

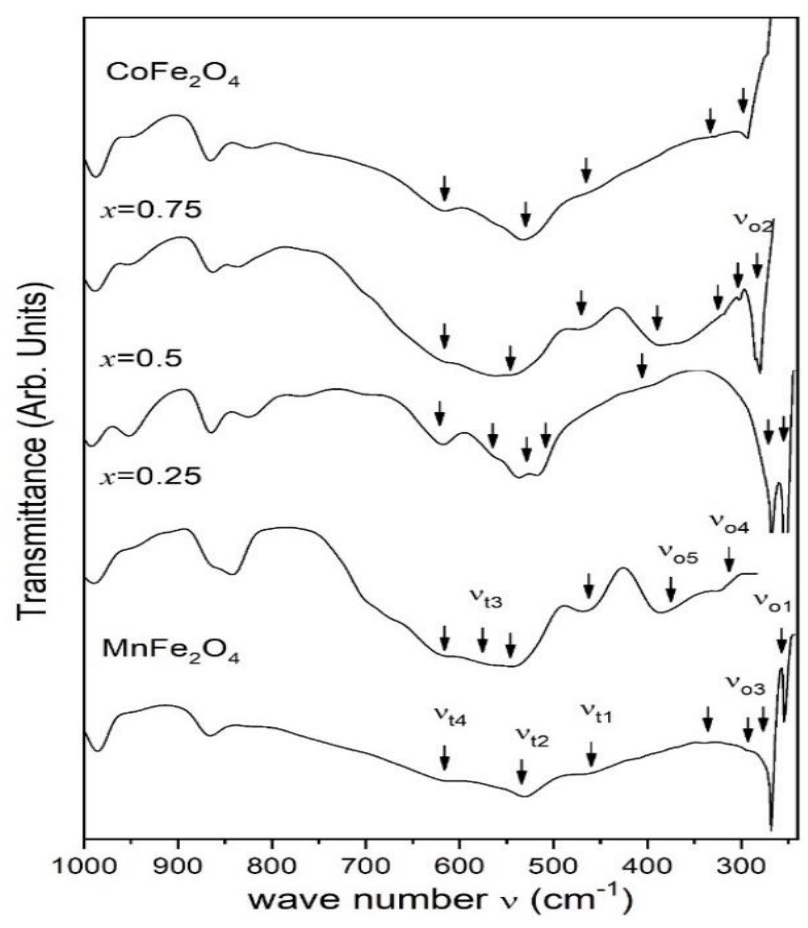

Fig (5): FTIR measurements of different $\mathrm{Mn}_{1-x} \mathrm{Co}_{x} \mathrm{Fe}_{2} \mathrm{O}_{4}$ nanoparticles

\subsection{Fourier-transform infrared (FTIR) spectroscopy}

The FTIR spectra of the different $\mathrm{Mn}_{1-x} \mathrm{Co}_{x} \mathrm{Fe}_{2} \mathrm{O}_{4}$ $(x=0,0.25,0.5,0.75$, and 1) nanoparticles are shown Figure (5). The two characteristic vibrational bands; $v_{t}$ (450-650 cm-1) and $v_{0}\left(250-400 \mathrm{~cm}^{-1}\right)$ belong to the tetrahedral and octahedral sites, respectively. Each band contains more than one vibrational frequency, which can be attributed to the difference in the atomic masses of different ions ( $\mathrm{Fe}, \mathrm{Mn}$, and $\mathrm{Co}$ ), bond lengths, and the correlation between A-site complexes and the B-site [2124]. The presence of secondary $\mathrm{Mn}$ oxide phases for samples $\mathrm{Mn}_{1-x} \mathrm{Co}_{x} \mathrm{Fe}_{2} \mathrm{O}_{4}(x=0,0.25,0.5)$ will logically complicate the FTIR response and cause additional vibrational frequencies. The bond length in the A-site is shorter than that in the B-site, hence, stretching the cation-O bond in the A-site, which will require a higher energy than that required for the cation-O bond in the Bsite [24,25]. This fact causes a higher tetrahedral vibrational band than that for the $\mathrm{B}$ band. The vibrational frequencies of all samples are listed in Table (2). The tetrahedral and octahedral sites force constants $\left(k_{\mathrm{t}}\right.$ and $k_{0}$, respectively) can be calculated as [26]:

$$
\begin{aligned}
& k_{t}=7.62 \times M_{A} \times v_{t}^{2} \times 10^{-7} \mathrm{~N} / \mathrm{m} \\
& k_{o}=10.62 \times \frac{M_{A}}{2} \times v_{o}^{2} \times 10^{-7} \mathrm{~N} / \mathrm{m}
\end{aligned}
$$

The average molecular weights of the cations in the tetrahedral and octahedral sites are $\mathrm{M}_{\mathrm{A}}$, and $\mathrm{M}_{\mathrm{B}}$ and were calculated using the cation distribution 
$(\mathrm{Fe})_{\mathrm{A}}\left[\mathrm{Mn}_{1-x} \mathrm{Co}_{x} \mathrm{Fe}_{\mathrm{B}} \mathrm{O}_{4}\right.$. Figure (6a) illustrates the average force constant $k_{\mathrm{tav}}$ and $k_{\mathrm{oav}}$ in both $\mathrm{A}$ - and $\mathrm{B}$ sites. Because of the shorter bond in the A-site, the bond in the tetrahedral site is stronger than that in the octahedral site and hence, $k_{\mathrm{t}}>k_{\mathrm{o}}$. The force constant is sensitive to the bond length, charge, mass, and size of the ions forming these bonds [25,27]. In the A-site, $k_{\mathrm{t}}$ changes with increasing $x$, however, no specific trend was observed. Alternatively, $k_{\mathrm{o}}$ increases slightly with increasing $x$ up to 0.5 and then it slowly decreases.
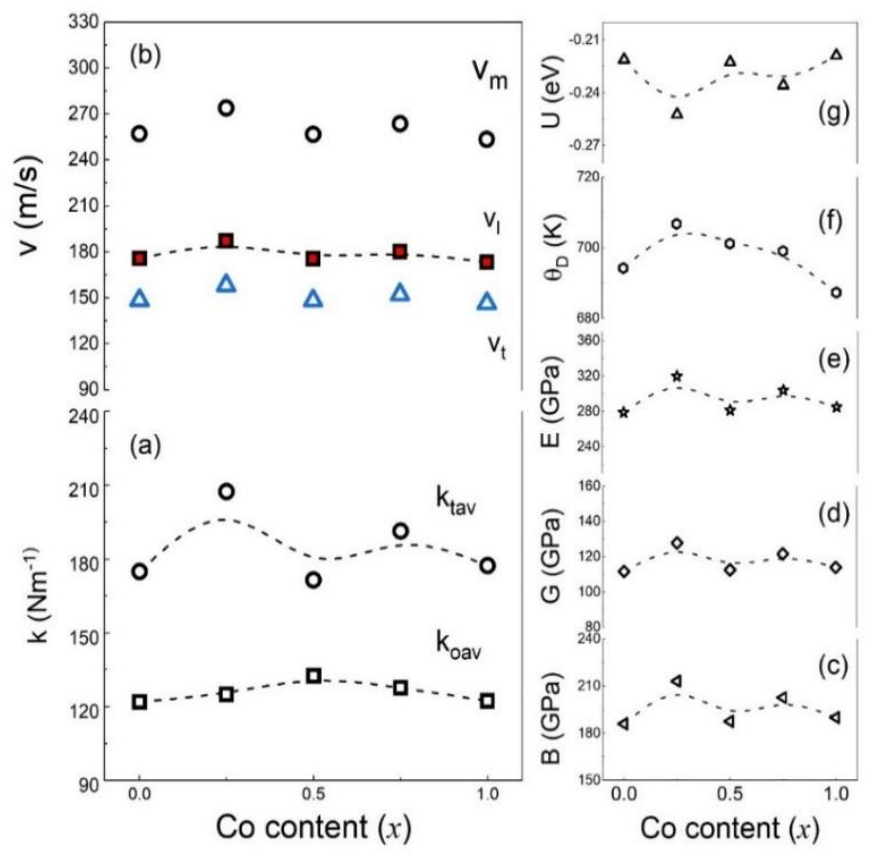

Fig. ( 6 a): Force constant $k$, b) velocity of elastic waves $\left(V_{l}, V_{t}\right.$ and $V_{m}$ ), c) Bulk modulus (B), d) Young's modulus (E) e) rigidity modulus (G). f) Debye temperature $(\theta \mathrm{D})$ and $\mathrm{g}$ ) lattice energy (U) of different elastic parameters of different $\mathrm{Mn}_{1-x} \mathrm{Co}_{x} \mathrm{Fe}_{2} \mathrm{O}_{4}$ nanoparticles
The average stiffness relates to the bulk modulus $(B)$ as:

$$
\mathrm{B}=\frac{\mathrm{k}}{a}
$$

Where $a$ is the lattice constant obtained from the XRD measurements. Different elastic parameters can be calculated as [26-28]:

The longitudinal velocity of elastic waves $\left(V_{1}\right)$

$$
v_{l}=\left[\frac{9 B}{5 \rho_{x}}\right]^{\frac{1}{2}}
$$

The transverse velocity

of elastic waves $\left(V_{\mathrm{t}}\right)$

$$
v_{t}=\left[\frac{3 B}{5 \rho_{x}}\right]^{\frac{1}{2}}
$$

The mean velocity of elastic waves $\left(V_{\mathrm{m}}\right)$

$$
v_{m}=\left[\frac{1}{3}\left(\frac{2}{v_{t}^{3}}+\frac{1}{v_{l}^{3}}\right)\right]^{\frac{-1}{3}}
$$

The rigidity modulus $(\mathrm{G})$

$$
G=\rho_{x} v_{t}^{2}
$$

Young's modulus (E)

$$
E=\frac{9 \mathrm{BG}}{3 \mathrm{~B}+\mathrm{G}}
$$

\begin{tabular}{|c|c|c|c|c|c|c|c|c|c|c|c|}
\hline$x$ & $v_{A 1}$ & $\mathbf{v}_{\mathbf{A} 2}$ & $\mathbf{v}_{\mathrm{A} 3}$ & $v_{A 4}$ & $v_{\text {Aav }}$ & VB1 & $v_{B 2}$ & $v_{B 3}$ & $v_{B 4}$ & VB5 & VBav \\
\hline & \multicolumn{11}{|c|}{$\left(\mathrm{cm}^{-1}\right)$} \\
\hline 0 & 462 & - & 530.4 & 613.3 & 535.3 & 254.6 & 265.7 & 293.2 & 341.4 & 387.7 & 308.5 \\
\hline 0.25 & 468.7 & - & 542 & 615.3 & 542 & - & - & 297 & 324.9 & 385.8 & 335.9 \\
\hline 0.5 & - & 516.9 & 538.1 & 619.1 & 558 & 254.6 & 268.1 & - & - & 393.5 & 305.4 \\
\hline 0.75 & 470.6 & - & 555.5 & 617.2 & 547.8 & 279.7 & - & 302.8 & 322.1 & 385.8 & 322.6 \\
\hline 1 & 461 & - & 532.3 & 615.3 & 536.2 & 293.2 & - & - & 327.9 & - & 310.5 \\
\hline
\end{tabular}

The lattice energy $(\mathrm{U}) \quad \mathrm{U}=-3.108\left(M v_{m}\right) \times 10^{-12}$

Table (2): Tetrahedral and octahedral vibrational frequencies ( $v_{t 1}, v_{t 2}, v_{t a v}, v_{01}, v_{02}, v_{03}$, and $\left.v_{0 a v}\right)$ of the $\mathrm{Mn}_{1-x} \mathrm{Co}_{x} \mathrm{Fe}_{2} \mathrm{O}_{4}$ nanoparticles 
The values of the longitudinal $\left(V_{1}\right)$, transverse $\left(V_{\mathrm{t}}\right)$, mean $\left(V_{\mathrm{m}}\right)$ velocity, and the elastic parameters; B, G, E, and $\mathrm{U}$ are shown in Figure (6). Three main factors that govern the behavior of all these parameters are as follows:

i) The change in the lattice parameter will affect the density and length of the bonds in both sites, as shown before in the XRD measurements. As motioned before, $a$ decreases with increasing the Co content, however, this decrease is not uniform. The decreasing of the lattice parameter tends to increase the force constant and consequently, the elastic parameters; B, G, and E.

ii) The particle size $\mathrm{D}$ is higher for the Co substituted samples. Increasing the particle size tends to decrease the elastic moduli; B, G, and E [21].

iii) The presence of the secondary $\mathrm{Mn}$ oxide phases for samples $\mathrm{Mn}_{1-x} \mathrm{Co}_{x} \mathrm{Fe}_{2} \mathrm{O}_{4}(x=0,0.25,0.5)$ will affect the elastic moduli.

For all the calculated parameters, $V_{\mathrm{l}}, V_{\mathrm{t}}, V_{\mathrm{m}}, \mathrm{B}, \mathrm{G}$, and $\mathrm{E}$, no specific dependence on $x$ was observed. Such behavior suggests that the motioned i,ii and iii factors are variable for each sample, non-uniform and the resultant effect has no systematic dependence on the Co content.

The Debye temperature $\left(\theta_{\mathrm{D}}\right)$ can be obtained from the Waldron method as [26]:

$$
\theta_{D}=\frac{h c v_{a v}}{k}
$$

Where $h$ is the Planck's constant, $c$ is the velocity of light, and $k_{\mathrm{B}}$ is the Boltzmann constant. $\theta_{\mathrm{D}}$ increases with the initial doping of $\mathrm{Co}^{2+}$ ions $(x=0.25)$ and then it decreases gradually. As observed before for $\mathrm{CoFeAlO}_{4}$, Debye decreases with the increase of the particle size, whereas, smaller ferrite nanoparticles have stiffer crystals [21].

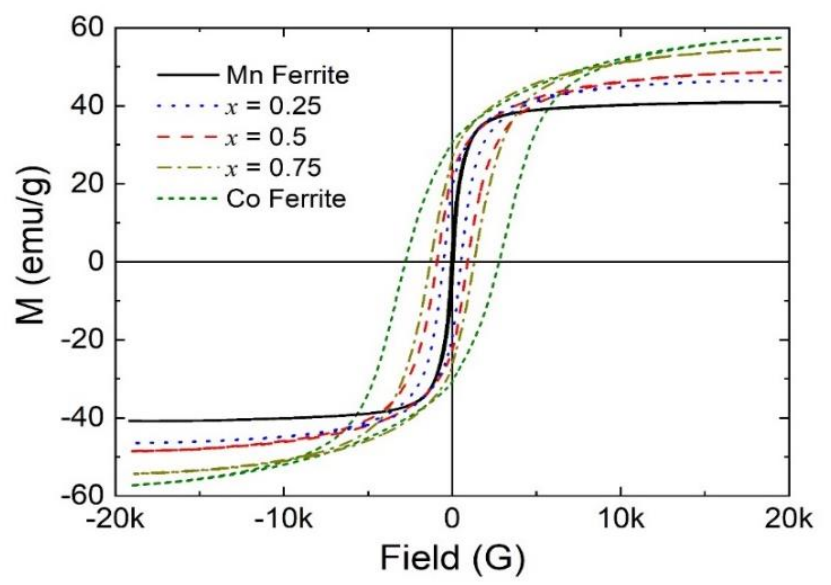

Fig (7): Room temperature hysteresis loops of different $\mathrm{Mn}_{1}$ ${ }_{x} \mathrm{Co}_{x} \mathrm{Fe}_{2} \mathrm{O}_{4}$ nanoparticles

\subsection{Vibrating sample magnetometer (VSM) measurements}

Room temperature hysteresis loops of different $\mathrm{Mn}_{1-x} \mathrm{Co}_{x} \mathrm{Fe}_{2} \mathrm{O}_{4}$ nanoparticles are shown in Figure (7).
The saturation magnetization $\left(\mathrm{M}_{\mathrm{s}}\right)$, coercivity $\left(\mathrm{H}_{\mathrm{c}}\right)$, remanent magnetization $\left(\mathrm{M}_{\mathrm{r}}\right)$, and the squareness ratio are listed in Table (3). The saturation magnetization increases linearly with increasing $x . \mathrm{M}_{\mathrm{s}}$ can be expressed in the Bohr magneton unit as:

$M_{o b s}=\frac{\text { (saturation magnetization }) \times(\text { molecular weight })}{5585}$

The values of the observed moment $\mathrm{M}_{\mathrm{obs}}$ are shown in Table (3) and Figure (8). The magnetic properties of the ferrites originated mainly by A-A, A-B, and B-B magnetic super exchange interactions. According to Néel's Model, the magnetic moment $\mathbf{M}_{\mathrm{cal}}$ is described by[8]:

$$
M_{\text {cal }}=M_{B}-M_{A}
$$

The tetrahedral moment $\mathrm{M}_{\mathrm{A}}$ and octahedral moment $\mathrm{M}_{\mathrm{B}}$ were calculated using the cation distribution $(\mathrm{Fe})_{\mathrm{A}}\left[\mathrm{Mn}_{1-x} \mathrm{Co}_{x} \mathrm{Fe}\right]_{\mathrm{B}} \mathrm{O}_{4}$ and the magnetic moment of $\mathrm{Co}^{2+}, \mathrm{Fe}^{3+}$ ions are $2 \mu_{\mathrm{B}}$ and $5 \mu_{\mathrm{B}}$, respectively. $\mathrm{Mn}^{2+}$ ions with $\left(\mathrm{d}^{5}\right)$ can have two magnetic moments; high spin with $5 \mu_{\mathrm{B}}$ and low spin with $1 \mu_{\mathrm{B}}$. The low values $\mathrm{M}_{\mathrm{obs}}$ indicate the low spin state of $\mathrm{Mn}^{2+}$ ions. The values of $\mathrm{M}_{\mathrm{cal}}$ are presented in Table (3) and Figure (8). $\mathrm{M}_{\mathrm{r}}$ also increases gradually with the increase in $x$, but with a faster rate than that of $M_{s}$. Therefore, the squareness ratio $\mathrm{M}_{\mathrm{r}} / \mathrm{M}_{\mathrm{s}}$ increases gradually with an increase of the Co content and reflects a gradual increase of the particle size. The values of the squareness suggest that different $\mathrm{Mn}_{1-x} \mathrm{Co}_{x} \mathrm{Fe}_{2} \mathrm{O}_{4}$ nanoparticles have uniaxial anisotropy, which arises due to surface effects [29].
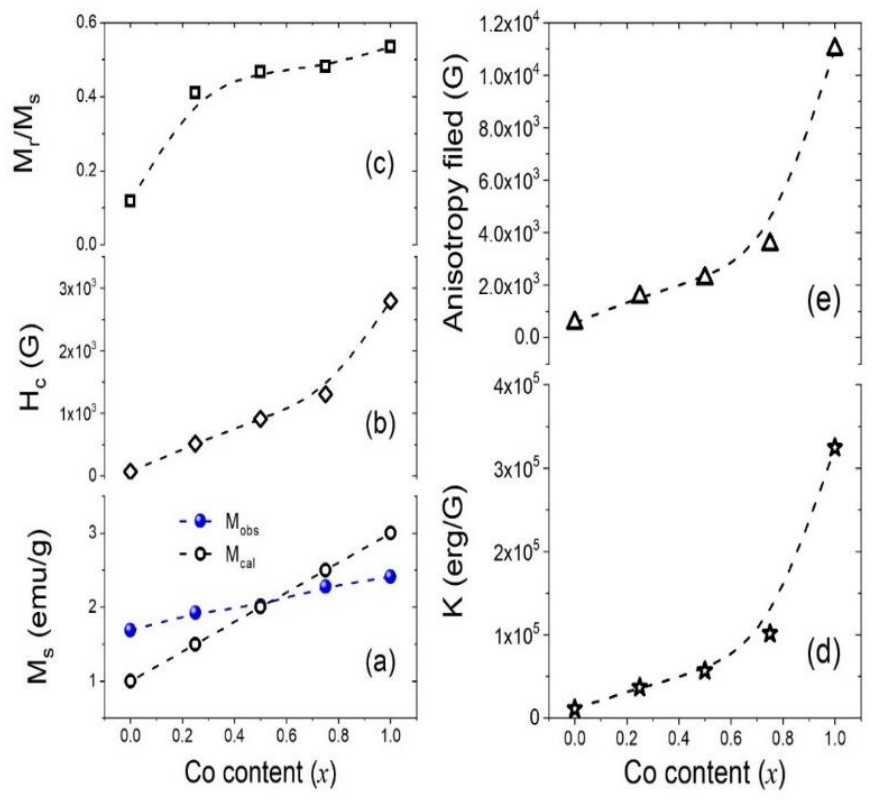

Fig. (8): Magnetic parameters of different $\mathrm{Mn}_{1-x} \mathrm{Co}_{x} \mathrm{Fe}_{2} \mathrm{O}_{4}$ nanoparticles a) The observed moment $\left(\mathrm{M}_{\mathrm{obs}}\right)$, and calculated moment (Mcal), b) Coercivity $\left(\mathbf{H}_{c}\right)$, c) Squareness ratio, d) Effective magnetic anisotropy constant (K), and e) Anisotropy field $\left(\mathrm{H}_{\mathrm{a}}\right)$

Arab J. Nucl. Sci. Appl., Vol. 55, 2, (2022) 
The coercivity $\left(\mathrm{H}_{\mathrm{c}}\right)$ increases dramatically with increasing $x$, from $66 \mathrm{G}$ for $\mathrm{MnFe}_{2} \mathrm{O}_{4}$ to almost $2794 \mathrm{G}$ for $\mathrm{CoFe}_{2} \mathrm{O}_{4}$. Such an increase in coercivity suggests a gradual move from soft ferrite to hard ferrite by increasing the Co content. $\mathrm{M}(\mathrm{H})$ can be fitted by the law approach to saturation as [30]:

$$
M(H)=M_{s}\left(1-\frac{\mathrm{a}}{H}-\frac{\mathrm{b}}{H^{2}} \ldots\right)+\chi_{0} H
$$

For a uniaxial symmetry, the coefficient $\mathrm{b}$ relates to the effective magnetic anisotropy constant [30]:

$$
b=\frac{4}{15}\left(\frac{\mathrm{K}}{\mu_{0} M_{S}}\right)^{2}
$$

The anisotropy field $\left(\mathrm{H}_{\mathrm{a}}\right)$ can be obtained from [30]:

$$
H_{a}=\frac{2 \mathrm{~K}}{\mu_{0} M_{S}}
$$

The fitting of hysteresis loops of different $\mathrm{Mn}_{1-}$ ${ }_{x} \mathrm{Co}_{x} \mathrm{Fe}_{2} \mathrm{O}_{4}$ nanoparticles are shown in Figure (9). The calculated effective magnetic anisotropy constant $(\mathrm{K})$ is presented in Table (3) and Figure (8d). The strong increase of $\mathrm{H}_{c}$ is mainly originated by the enhanced values of $\mathrm{K}$ and $\mathrm{H}_{\mathrm{a}}$ with increasing the Co content. Both $\mathrm{K}$ and $\mathrm{H}_{\mathrm{a}}$ depend on the type and concentration of magnetic ions in the ferrite system. Even more, the particle size and shape strongly affect the values of the magnetic anisotropy constant and the anisotropy field. All these factors are present in the $\mathrm{Mn}_{1-x} \mathrm{Co}_{x} \mathrm{Fe}_{2} \mathrm{O}_{4}$ nanoparticles. Accordingly, the changes in the values of the magnetic parameters can be attributed to the interplay between the change in the Co content and the particle size.
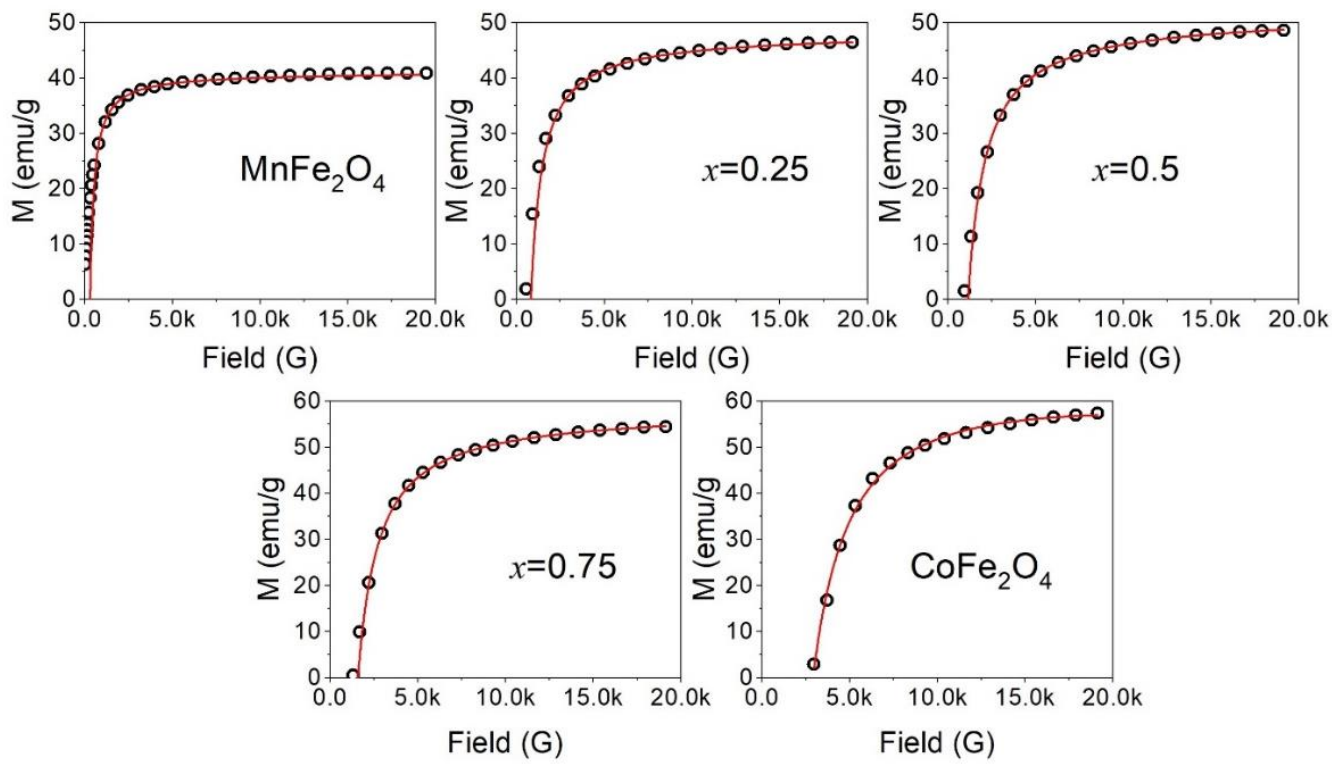

Fig. (9): Fitting of room temperature hysteresis loops of different $\mathrm{Mn}_{1-x} \mathrm{Co}_{x} \mathrm{Fe}_{2} \mathrm{O}_{4}$ nanoparticles using Eq. (21)

Table (3): saturation magnetization $\left(M_{s}\right)$, coercivity $\left(H_{c}\right)$, remanent magnetization $\left(M_{r}\right)$, the squareness ratio $\left(\mathbf{R}^{2}=\mathbf{M}_{\mathrm{r}} / \mathbf{M}_{\mathrm{s}}\right)$, observed moment $\mathbf{M}_{\mathrm{obs}}$, calculated moment $\mathbf{M}_{\mathrm{cal}}$, fitting parameters Ms(fit), and anisotropy constant $(\mathrm{K})$, and anisotropy field $\left(\mathrm{H}_{\mathrm{a}}\right)$ of $\mathrm{Mn}_{1-x} \mathrm{Co}_{x} \mathrm{Fe}_{2} \mathrm{O}_{4}$ nanoparticles

\begin{tabular}{ccccccc}
\hline & & $\mathbf{0}$ & $\mathbf{0 . 2 5}$ & $\mathbf{0 . 5}$ & $\mathbf{0 . 7 5}$ & $\mathbf{1}$ \\
\hline $\mathrm{M}_{\mathrm{s}}$ & $(\mathrm{emu} / \mathrm{g})$ & 40.88 & 46.46 & 48.59 & 54.43 & 57.38 \\
$\mathrm{H}_{\mathrm{c}}$ & $(\mathrm{G})$ & 66.36 & 515.88 & 906.04 & 1302.7 & 2793.5 \\
$\mathrm{M}_{\mathrm{r}}$ & $(\mathrm{emu} / \mathrm{g})$ & 4.84 & 19.05 & 22.68 & 26.22 & 30.66 \\
$\mathrm{M}_{\mathrm{r}} / \mathrm{M}_{\mathrm{s}}$ & & 0.118 & 0.41 & 0.467 & 0.482 & 0.534 \\
$\mathrm{M}_{\mathrm{obs}}$ & $(\mu \mathrm{B})$ & 1.69 & 1.93 & 2.02 & 2.28 & 2.41 \\
$\mathrm{M}_{\mathrm{cal}}$ & $(\mu \mathrm{B})$ & 1 & 1.5 & 2 & 2.5 & 3 \\
$\mathrm{M}_{\mathrm{s}}(\mathrm{Fit})$ & $(\mathrm{emu} / \mathrm{g})$ & 40.87 & 47.68 & 50.41 & 57.29 & 58.99 \\
$\mathrm{~K}$ & $(\mathrm{erg} / \mathrm{G})$ & 11288.3 & 37078.6 & 56990.8 & 101770.1 & 324425.1 \\
$\mathrm{H}_{\mathrm{a}}$ & $(\mathrm{G})$ & 552.37 & 1555.3 & 2261.3 & 3552.73 & 11000.3 \\
\hline
\end{tabular}




\section{CONCLUSION}

$\mathrm{Mn}_{1-x} \mathrm{Co}_{x} \mathrm{Fe}_{2} \mathrm{O}_{4}$ nanoparticles were successfully synthesized using the Sol-gel technique. The effect of increasing the Co content on the structural, elastic and magnetic properties were investigated. The X-ray powder diffraction measurements confirmed the formation of the face center cubic spinel phase. The secondary phase in the samples $(x \leq 0.5)$ disappeared with increasing the cobalt content. The experimental lattice parameter $a_{\text {exp }}$, obtained by fitting the XRD patterns using Maud program, decreased by increasing $x$, and showed a good agreement with the theoretically calculated $a_{\text {th }}$. The differences in the values and behavior of the particle size obtained from W-H plots $\left(\mathrm{D}_{\mathrm{W}-\mathrm{H}}\right)$ and the particle size obtained from the Maud fitting can be attributed to the existence of the secondary Mn oxide phases for $x<0.5$. FTIR spectra revealed the formation of the cubic spinel phase, whereas, the tetrahedral and octahedral vibrational bands were observed. The magnetic parameters; saturation magnetization $\left(\mathrm{M}_{\mathrm{s}}\right)$, coercivity $\left(\mathrm{H}_{\mathrm{c}}\right)$, remanent magnetization $\left(\mathrm{M}_{\mathrm{r}}\right)$ and the squareness ratio increased with increasing the Co content. The values of $\mathrm{M}_{\mathrm{s}}$ suggested that $\mathrm{Mn}^{2+}$ ions are in a low spin state $\left(1 \mu_{\mathrm{B}}\right)$, therefore, increasing $x$ will logically increase the saturation magnetization. The strong increase in the coercivity values with increasing $x$ confirmed the transition from soft Mn-ferrite toward hard Co-doped Mn ferrite system.

\section{REFERENCES}

[1] T. Nishimura, A.M.A Hassan, M. Tomitori, Electrochemical etching of metal wires in lowstress electric contact using a liquid metal electrode to fabricate tips for scanning tunneling microscopy, Appl. Surf. Sci. 284 (2013) 715-719.

[2] A.M.A Hassan, T. Nishimura, A. Sasahara, H. Murata, M. Tomitori, Stable alignment of 4, 4"diamino-p-terphenyl chemically adsorbed on a $\mathrm{Si}$ (001)-(2× 1) surface observed by scanning tunneling microscopy, Surf. Sci. 630 (2014) 96100.

[3] Z.K. Heiba, N.G. Imam, Mohamed Bakr Mohamed, Temperature dependent cation distribution correlated with optical and magnetic properties of nanocrystalline $\mathrm{NiFe}_{1.8} \mathrm{Gd}_{0.2} \mathrm{O}_{4}$, J. Mol. Struct. 1095 (2015) 61-68.

[4] Z.K. Heiba, Mohamed Bakr Mohamed, L. Arda, N. Dogan, Cation distribution correlated with magnetic properties of nanocrystalline gadolinium substituted nickel ferrite, J. Magn. Magn. Mater. 391 (2015) 195-202.

[5] A.M. Wahba, Mohamed Bakr Mohamed, N.G. Imam, Correlating structural, magnetic, and luminescence properties with the cation distribution of $\mathrm{Co}_{0.5} \mathrm{Zn}_{0.5+x} \mathrm{Fe}_{2-x} \mathrm{O}_{4}$ nanoferrite, J. Magn. Magn. Mater. 408 (2016) 51-59.

[6] Mohamed Bakr Mohamed, K. El-Sayed, Structure and Microstructure in Relation to Magnetic/Dielectric Properties of Nanocrystalline $\mathrm{Ni}_{1-x} \mathrm{Zn}_{x} \mathrm{Fe}_{1.5} \mathrm{Cr}_{0.5} \mathrm{O}_{4}$ Ferrite, J. Supercond. Nov. Magn. 28 (2015) 2121-2131.

[7] M. Yehia, S.M. Ismail, A. Hashhash, Structural and magnetic studies of rare-earth substituted nickel ferrites. J. Supercond. Nov. Magn. 27 (2014) 771.

[8] S.M. Ismail, M. Yehia, S.S. Ata-Allah, Influence of Zinc Doping on the Structural and Magnetic Properties of Ni-Ga-Sm Polycrystalline Ferrites, Journal of Superconductivity and Novel Magnetism 28 (2015) 2875-2880.

[9] O.M. Hemeda, A. Tawfik, A.M.A. Henaish, B.I. Salem, Spectral, Electrical, Thermoelectrical and Dielectric Properties of ( $\mathrm{Zn}, \mathrm{Zr})$ Co-doped $\mathrm{CuFe}_{2} \mathrm{O}_{4}$, Journal of Superconductivity and Novel Magnetism 31 (2018) 3733.

[10] E.A. Arrasheed, T.M. Meaz, R.M. Shalaby, B.I. Salem, O.M. Hemeda, Rietveld refinement, cation distribution, morphological and magnetic study of $\mathrm{NiAl}_{x} \mathrm{Fe}_{2-x} \mathrm{O}_{4}$ nanoparticles, Applied Physics A 127 (2021) 1.

[11] M. Yehia, Sh Labib, S.M. Ismail, Structural and magnetic properties of nano- $\mathrm{NiFe}_{2} \mathrm{O}_{4}$ prepared using green nanotechnology. Phys. B 446 (2014) 49.

[12] A.M.A. Henaish, O.M. Hemeda, A. Alqarni, D.E. El Refaay, S. Mohamed, M.A. Hamad, The role of flash auto-combustion method and Mn doping in improving dielectric and magnetic properties of $\mathrm{CoFe}_{2} \mathrm{O}_{4}$, Applied Physics A 126 (2020) 1.

[13] A.M.A. Henaish, O.M Hemeda, BI Salem, FS ElSbakhy, $\mathrm{T}$ Khalass, Structural, magnetic and electrical properties of nano $\mathrm{NiCr}_{x} \mathrm{Fe}_{2-x} \mathrm{O}_{4}$ synthesized by flash auto combustion method, Journal of Physics: Conference Series 1253 (2019) 012025 .

[14] F.S. El-Sbakhy, M.I. Abdel-Ati, A.M. Abdelghany, O.M. Hemeda, Structural, spectral, rietveld 
refinement and cation distribution of nanoferrite $\mathrm{NiFe}_{2} \mathrm{O}_{4}$ doped with $\mathrm{Mn}$, The European Physical Journal Plus 136 (2021) 1-17.

[15] S.F. Mansour, O.M. Hemeda, S.I. El-Dek, B.I. Salem, Influence of $\mathrm{La}$ doping and synthesis method on the properties of $\mathrm{CoFe}_{2} \mathrm{O}_{4}$ nanocrystals, Journal of magnetism and magnetic materials $\mathbf{4 2 0}$ (2016) 7.

[16] M. Ferrari and L. Lutterotti, Method for the simultaneous determination of anisotropic residual stresses and texture by X-ray diffraction, J. Appl. Phys. 76 (1994) 7246-55.

[17] A. Dean John, Lange's Handbook of chemistry, McGRAW-HILL, INC. (1999).

[18] H. Irfan, M. Racik, S. Anand, Microstructural evaluation of $\mathrm{CoAl}_{2} \mathrm{O}_{4}$ nanoparticles by Williamson-Hall and size-strain plot methods. J. Asian Ceramic Soc. 6 (2018) 54-62.

[19] F. Zhang, Q. Jin, S.W. Chan, Ceria nanoparticles: size, size distribution, and shape. J. Appl. Phys. 95 (2004) 4319-4326.

[20] M. Satalkar, S.N. Kane, On the study of structural properties and cation distribution of $\mathrm{Zn}_{0.75}$ ${ }_{x} \mathrm{Ni}_{x} \mathrm{Mg}_{0.15} \mathrm{Cu}_{0.1} \mathrm{Fe}_{2} \mathrm{O}_{4}$ nano ferrite: effect of $\mathrm{Ni}$ addition. J. Phys. 755 (2016) 012050.

[21] T.M. Ali, S.M. Ismail, S.F. Mansour, M. A. Abdo, M. Yehia, Physical properties of Al-doped cobalt nanoferrite prepared by citrate-nitrate auto combustion method. J. Mater. Sci.: Mater. Electron. 32 (2021) 3092-3103.

[22] J.M. Thompson, Infrared Spectroscopy (Pan Stanford Publishing Pte. Ltd., Singapore, (2018).

[23] V. Rathod, A.V. Anupama, R. Vijaya Kumar, V.M. Jali, B. Sahoo, Correlated vibrations of the tetrahedral and octahedral complexes and splitting of the absorption bands in FTIR spectra of $\mathrm{Li}-\mathrm{Zn}$ ferrites. Vib. Spectrosc. 92 (2017) 267-272.

[24] B.J. Yang, H. Shin, H.K. Lee, H. Kim, A combined molecular dynamics/micromechanics/finite element approach for multiscale constitutive modeling of nanocomposites with interface effects. Appl. Phys. Lett. 103 (2013) 241903.

[25] A. Rais, K. Taibi, A. Addou, A. Zanoun, Y. AlDouri, Copper substitution effect on the structural properties of nickel ferrites. Ceram. Int. 40 (2014) 14413-14419.

[26] K.B. Modi, M.K. Rangolia, M.C. Chhantbar, H.H. Joshi, Study of infrared spectroscopy and elastic properties of fine and coarse grained nickelcadmium ferrites. J. Mater. Sci. 41 (2006) 73087318 .

[27] M.S. Gumaan, Chromium improvements on the mechanical performance of a rapidly solidified eutectic Sn-Ag alloy. J. Mater. Sci. Mater. Electron. 31 (2020) 10731-10737.

[28] M. Deepty, Ch. Srinivas, E. Kumar, N. Ranjith Mohan, C.L. Krisha Prajapat, T.V. Chandrasekhar Rao, S.S. Meena, A.K. Verma, D.L. Sastry, XRD, EDX, FTIR and ESR spectroscopic studies of coprecipitated Mn-substituted Zn-ferrite nanoparticles. Ceram. Int. 45 (2019) 8037-8044.

[29] M. Yehia, A. Hashhash, Structural and magnetic study of $\mathrm{Sm}$ doped $\mathrm{NiFe}_{2} \mathrm{O}_{4}$ nanoparticles, Journal of Materials Science: Materials in Electronics 30 (2019) 6768-6775.

[30] Caizer C. Nanoparticle Size Effect on Some Magnetic Properties. In: Aliofkhazraei M. (eds) Handbook of Nanoparticles. Springer, Cham. (2015). 